\title{
The Role of Interventional Radiology in the Management of Pancreatic Pathologies
}

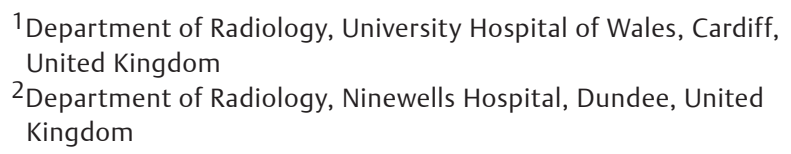

Ghali Salahia ${ }^{1}$ Sook Cheng Chin ${ }^{2}$ Ian Zealley ${ }^{2}$ Richard D. White

Address for correspondence Ghali Salahia, MD, MBA, Department of Radiology, University Hospital of Wales, Heath Park Way, Cardiff, CF14 4XW, United Kingdom (e-mail: gsalahia@hotmail.com).

J Gastrointestinal Abdominal Radiol ISGAR 2020;3:99-114

\begin{abstract}
Keywords

- interventional radiology

- pancreatic cancer

- pancreatic transplant

- pancreatitis

- peripancreatic collection

Pancreatic pathologies are varied and wide-ranging, and a multidisciplinary approach is essential for effective diagnosis and management. We describe image-guided percutaneous (nonendoscopic) interventions in the management of pancreatic disease, with emphasis on inflammatory and neoplastic pancreatic pathologies and on the transplanted pancreas. Image-guided treatments for the complications of pancreatitis include percutaneous interventions on simple and complex peripancreatic collections, pseudocysts, and fistulas. Vascular interventions predominantly focus on the treatment of pseudoaneurysms, hemorrhagic pseudocysts, and arteriovenous malformations. Emerging ablative techniques for pancreatic cancer are promising and include percutaneous radiofrequency ablation, microwave ablation, irreversible electroporation, and electrochemotherapy. Image-guided interventions on the transplanted pancreas commonly include percutaneous biopsy and drainage in addition to endovascular treatments of vascular complications.
\end{abstract}

\section{Introduction}

Approximately $20 \%$ of patients with acute pancreatitis will develop complications that require intervention. ${ }^{1}$ These can be classified into vascular and nonvascular complications ${ }^{2}$ :

- Nonvascular complications include collections, bowel complications, and pancreatic fistulas. ${ }^{2}$

- Vascular complications include peripancreatic arterial and venous pseudoaneurysms, venous thrombosis, and arteriovenous malformations (AVMs). ${ }^{3}$

Pancreatic adenocarcinoma is the 12th most common malignancy and the 7th leading cause of cancer-related mortality globally. ${ }^{4}$ Most patients present late with either locally extensive or metastatic disease. ${ }^{5}$ The aggressive nature, late presentation, and lack of effective therapies all contribute to the poor prognosis. Patients with more advanced disease will typically undergo either endoscopic ultrasound (US) or interventional radiology-guided interventions to deliver either palliative or preoperative care. ${ }^{4}$
Pancreas transplantation offers diabetic patients the prospect of glycemic control free of exogenous insulin administration, with a significant improvement in quality of life and reduction in diabetes-associated complications. ${ }^{6}$ Surgery can, however, be complicated by a high rate of early technical failure. ${ }^{7}$ Percutaneous and endovascular interventions are increasingly performed for the diagnosis of rejection and the treatment of vascular complications.

\section{Nonvascular Interventions}

\section{Drainage of Peripancreatic Collection}

Intra-abdominal collections and abscesses are the most common complication following acute pancreatitis. ${ }^{8}$ Collections are classified according to the revised Atlanta Classification into acute peripancreatic fluid collections, pseudocysts, acute necrotic collections, and walled-off pancreatic necro$\operatorname{sis}^{9,10}$ ( Fig. 1). Symptomatic intra-abdominal collections require imaging-guided drainage. When a collection is readily 

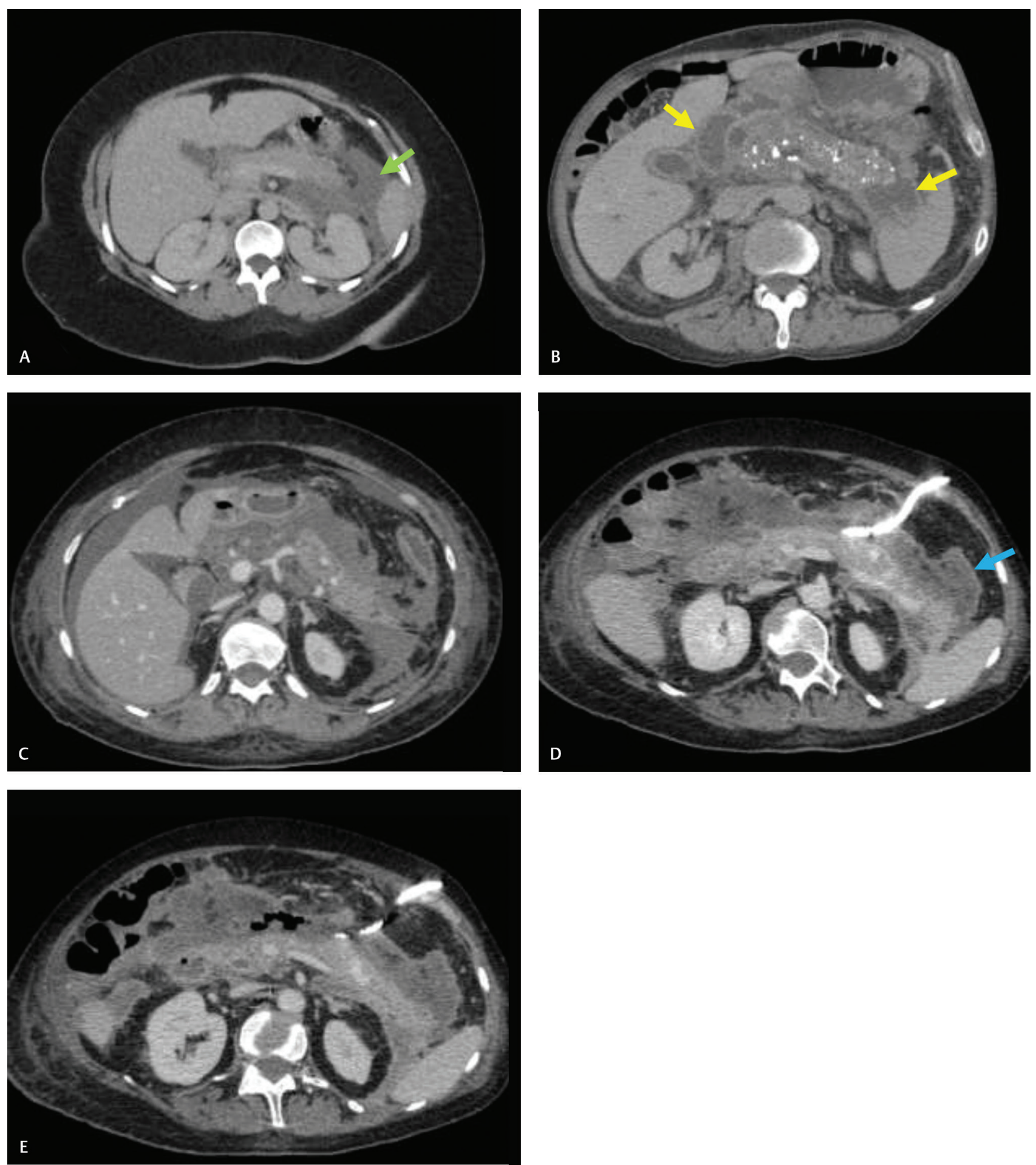

Fig. 1 (A) Acute peripancreatic fluid collection (green arrow). (B) Multiple pseudocysts (yellow arrows) in the context of acute on chronic pancreatitis (note the pancreatic calcifications). (C) Acute necrotic collection (note absent enhancement of the pancreatic head). (D) Percutaneously drained walled-off necrosis (blue arrow indicate the wall). (E) This had been subsequently infected (note the presence of gas).

visualized on US, US-guided percutaneous drainage placement is generally the preferred choice as US is less expensive, allows for real-time monitoring of the needle placement, and is free from ionizing radiation. ${ }^{11}$ However, the combination of US and fluoroscopy can improve on this by facilitating safe needle puncture using US guidance followed by optimal drain positioning using fluoroscopic guidance.
Infected pancreatic necrosis is often poorly marginated and nonenhanced and may contain bubbles of gas. However, these features are not always present, and necrotic collections without signs of infection at CT should be considered sterile until proven otherwise. Percutaneous drainage is generally avoided in this context due to the potential risk of introducing infection. Deteriorating patients with high 
clinical suspicion of infection may benefit from US-guided aspiration to rule out an infected pancreatic necrosis. When infected necrosis is present, large-bore or multiple percutaneous drainage catheters should be sited in the collection as a bridge or as an alternative to surgical debridement. ${ }^{12}$

Guidelines from 2013 by the International Association of Pancreatology and the American Pancreatic Association advise postponing all forms of invasive intervention in patients with infected necrosis, preferably until 4 weeks after the onset of disease. ${ }^{13}$ The rationale behind this is fourfold. First, antibiotics alone might be sufficient as treatment. Second, diagnosing infected necrotizing pancreatitis is often easier in the later stages of the disease, when all other sources of infection or systemic inflammatory response have been ruled out. Third, catheter drainage is typically easier once the collection has become more liquefied and the stage of walled-off necrosis has been reached. Fourth, endoscopic transluminal drainage requires a walled-off collection.

In theory, it is not always necessary to wait several weeks until full encapsulation of peripancreatic collections and percutaneous drainage can be performed safely and successfully in the first weeks after the onset of disease. ${ }^{14}$ If there is no technical reason for postponing catheter drainage, patients with infected necrotizing pancreatitis might benefit from earlier catheter drainage in terms of reducing the rate of complications and length of hospital stay. This is also the case in the context of abdominal compartment syndrome. More recently, the Dutch Pancreatitis Study Group is undertaking a randomized controlled trial (POINTER [postponed or immediate drainage of infected necrotizing pancreatitis]) that will compare immediate and delayed catheter drainage in an attempt to further improve the outcome of these severely ill patients. ${ }^{15}$

When a collection is located deep in the abdomen or is poorly visualized on US, computed tomography (CT) offers adequate guidance to allow safe placement of percutaneous drains. ${ }^{16}$

After placement and aspiration of fluid, self-locking pigtail drains of size 8 to $12 \mathrm{Fr}$ are left in place and irrigated with 10 to $20 \mathrm{~mL}$ of sterile saline three times daily. Catheters can be upsized to a maximum of $28 \mathrm{~F}$, as the clinical situation evolves if smaller drains prove inadequate. ${ }^{8}$

External drainage of peripancreatic collections may fail in the setting of abnormal pancreatic ductal anatomy. In a study by Nealon et al, there was a statistically significant difference in successful percutaneous drainage between patients with normal pancreatic duct anatomy and those with a pancreatic duct stricture or duct disconnection. ${ }^{17}$ Drainage failed to permanently resolve the collection in half of the patients with duct strictures and was uniformly unsuccessful in patients with ductal disconnection or occlusion.

The incidence of cyst-cutaneous fistula formation is reportedly as high as $50 \%$ in certain settings ${ }^{18}$; therefore internal transgastric drainage is preferable in situations in which a persistent pseudocyst is being driven by a persisting pancreatic duct fistula (-Fig. 2).

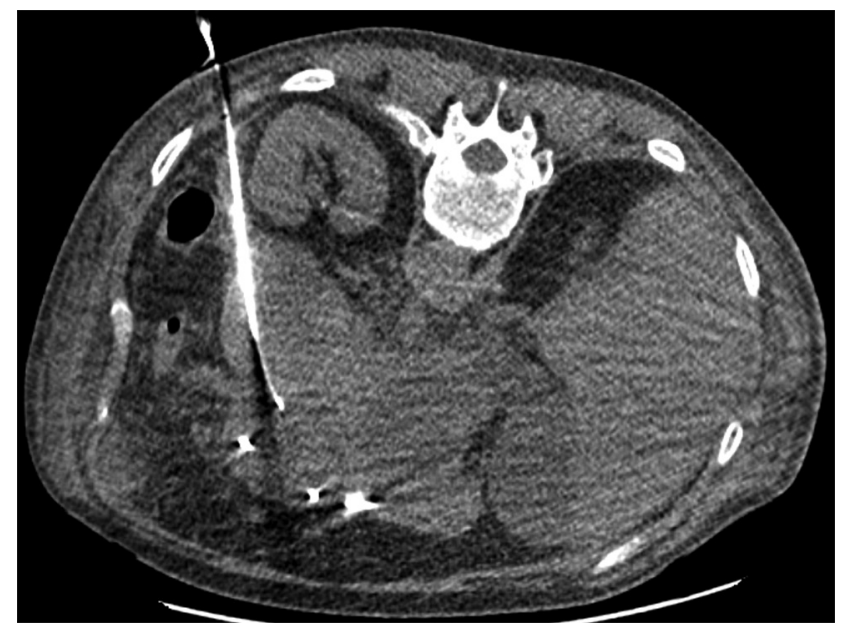

Fig. 2 CT-guided guided drainage of peripancreatic collection through a right posterior approach.

\section{Pseudocyst Gastrostomy}

Iatrogenic communication between a pseudocyst and hollow viscus can be formed to enable drainage ( - Fig. 3 ). Internal gastric drainage of pancreatic pseudocysts is now commonly performed under endoscopic US guidance. ${ }^{19} \mathrm{CT}$-guided percutaneous technique cannot regularly provide an adequately wide cystogastrostomy opening. ${ }^{11}$ Surgical cystogastrostomy is usually reserved for necrotic collections that do not abut the gastrointestinal tract and may be found in the retroperitoneal space. ${ }^{19}$

The percutaneous approach typically necessitates two stages, with the pseudocyst initially being drained percutaneously through a transgastric route as a temporary bridge before converting into an internal cystogastrostomy drainage through a double-J stent or by pushing the percutaneous drain into the stomach. ${ }^{20}$

There is no consensus about the duration of drainage through pseudocyst gastrostomy. After the introduction of this technique in 1984, pigtail catheter removal was initially advised after 3 months. The technique has since evolved such that the catheter is left in situ for at least 1 year to more than 3 years if there is a concern that catheter removal would lead to symptomatic recurrence. Catheter removal by forceps during routine gastroscopy in the outpatient setting has been reported. ${ }^{21}$

Technical success in percutaneous catheter placement is greater than $90 \%$, with an immediate complication rate of around $6 \%$ and a mortality rate of $1 \%{ }^{18}$ Secondary infection with abscess formation is not uncommon, occurring in around $11 \%{ }^{21}$ Complete resolution of the pseudocyst with this method has been reported in at least $88 \%$ of cases. ${ }^{18}$

\section{Fistula Treatment}

Pancreatic fistulas may complicate pancreatic surgery or necrotizing pancreatitis. ${ }^{22}$ They can communicate with bowel loops, liver, or other adjacent viscera. ${ }^{23}$

The incidence of gastrointestinal fistulation following acute pancreatitis is reportedly 3 to $47 \%$, with an associated increase in mortality of up to $34.7 \%$ in those with pancreatic colonic fistulae. ${ }^{24}$ 

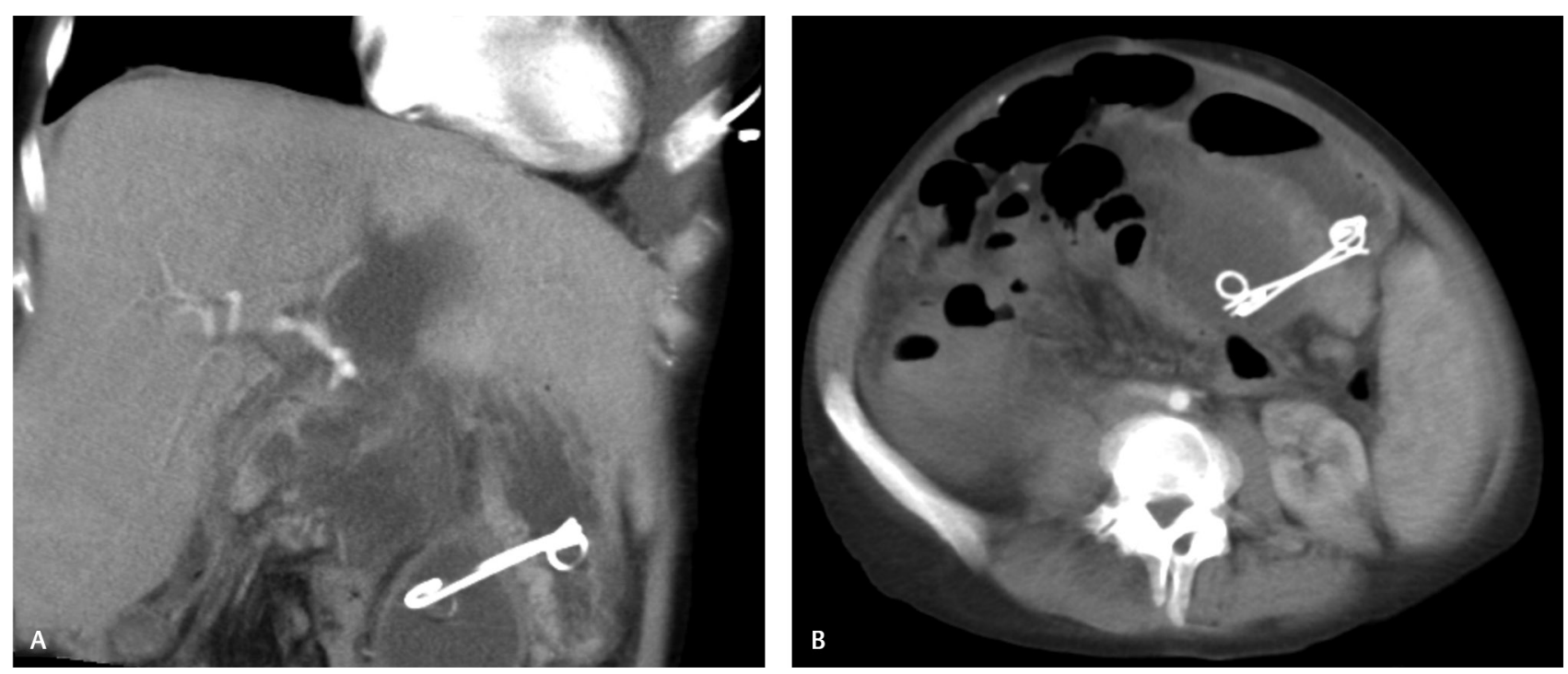

Fig. 3 (A, B) Coronal and axial maximum intensity projection reformatted CT (computed tomography) showing pseudocyst gastrostomy.

In the presence of a fluid collection, percutaneous drainage can treat the collection, and this may occasionally lead to spontaneous resolution of the fistula. ${ }^{16}$ If the main component of a fistula is of biliary origin, transhepatic biliary drain insertion can lead to fistula closure by diverting bile from the site of the fistula. In cases with persisting biliary leak, the placement of an occlusion balloon above the fistula may divert biliary flow away from the fistula. ${ }^{25}$

Direct fistula embolization has been found to be effective, with access gained through the tract of a previous surgical drain, through an image-guided percutaneous drain, or through a transhepatic approach. Once the fistula site has been reached, different materials may be used to facilitate closure, including ethanol, particles, or glue. ${ }^{16,26}$

\section{Percutaneous Necrosectomy}

Following liquefaction and encapsulation of necrotic pancreatic tissue, persistent infection of these cavities despite percutaneous drainage has been ascribed to the formation and infection of sequestered solid necrotic tissue that is presumed to be inaccessible to antibiotics. ${ }^{27}$ Surgical necrosectomy has historically been the mainstay of treatment for symptomatic patients. ${ }^{28}$ However, in the current era, when percutaneous or endoscopic drainage of pancreatic abscess/ infected necrotic collection fails, there may be a role for percutaneous necrosectomy in patients who are not fit for open or laparoscopic drainage. ${ }^{27}$

The procedure is performed by exchanging a preexisting left flank drain for a guidewire. Right-sided or transperitoneal drainage is also possible. ${ }^{29} \mathrm{~A}$ low-compliance balloon dilator is inserted into the collection and dilated to up to $30 \mathrm{Fr}$. Access to the cavity is achieved by passing a nephroscope (or similar) through a sheath, which allows debridement under direct vision. The nephroscope has an operating channel that permits standard $(5 \mathrm{~mm})$ laparoscopic graspers as well as an irrigation/suction channel. High-flow lavage promotes initial evacuation of pus and liquefied necrotic material, exposing residual black or gray devascularized pancreatic necrosis and peripancreatic fat, which, if loose, is extracted in a piecemeal fashion until, after several procedures, a cavity lined by viable granulation tissue is created. At the end of the procedure, an 8-Fr catheter sutured to a 24-Fr drain is passed into the cavity to allow continuous postoperative lavage of warm $0.9 \%$ normal saline. ${ }^{29}$ Chemically assisted debridement with hydrogen peroxide has been reported during endoscopic drainage. ${ }^{30}$

The necrotic pancreatic body and fatty tissue can also be fragmented using a snare catheter (LASSOS, Osypka Medical, Rheinfelden, Germany) and a Dormia basket advanced through the percutaneous sheath. ${ }^{27}$ Others described the use of a 14- to 16-Fr Malecot catheter (CR Bard Inc., Covington, Georgia) for debridement by twisting it repeatedly inside the collection. An endoscopic clamp through an appropriately sized introducer sheath can also be used percutaneously for the same purpose. ${ }^{31}$

\section{Vascular Interventions}

\section{Endovascular Treatment of Bleeding}

Peripancreatic Pseudoaneurysm Embolization

Pseudoaneurysms develop in approximately 4 to $8 \%$ of patients with chronic pancreatitis and less frequently in the context of acute pancreatitis. ${ }^{32,33}$ They most commonly affect the splenic artery followed by gastroduodenal, pancreaticoduodenal, and hepatic arteries. ${ }^{34}$

The etiology is attributed to an enzymatic insult to peripancreatic arteries or erosion of a pseudocyst into adjacent visceral arteries. Although rupture of a pseudoaneurysm is rare, it is a serious complication, potentially resulting in massive hemorrhage with concomitant significant clinical deterioration. A mortality rate of up to $37 \%$ has been reported. ${ }^{35}$

Early detection of pseudoaneurysms is important to prevent subsequent rupture and catastrophic outcomes (-Fig. 4). Abdominopelvic CT is the imaging modality of choice in patients with complicated pancreatitis. Images are obtained following intravenous administration of 100 to $150 \mathrm{~mL}$ of iodinated contrast material at a rate of 

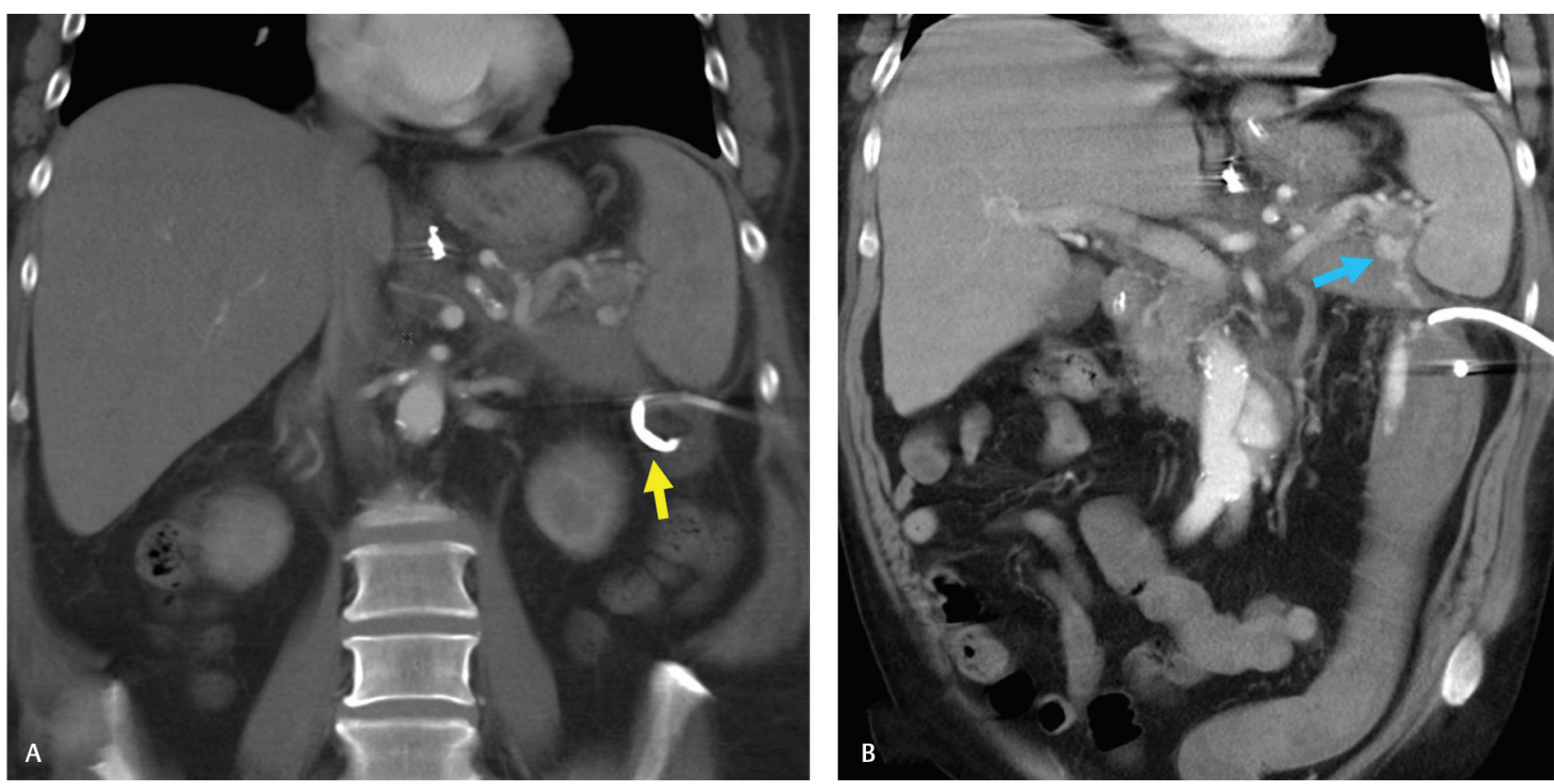

Fig. 4 A 48-year-old man with a peripancreatic collection as a sequel of acute pancreatitis was treated with a percutaneous drain (yellow arrow). Follow-up CT (computed tomography) during his admission revealed a splenic artery pseudoaneurysm, which was overlooked at the time of scanning (blue arrow). A few days later, the pseudoaneurysm ruptured and the patient presented with massive fresh rectal hemorrhage. As displayed in (B), The left flank drain has eroded its way into the descending colon, with side holes inside and outside the bowel.

$3.5 \mathrm{~mL} / \mathrm{second}$ or higher using a mechanical power injector. Craniocaudal pancreatic scanning is performed during breath-hold and commenced 30 to 50 seconds from the start of the contrast injection (pancreatic parenchymal phase). This imaging technique is suitable for the detection and follow-up of nonvascular complications of pancreatitis, as well as venous and most arterial complications. Detection of more subtle arterial complications (small pseudoaneurysms and subtle arterial hemorrhage) may require confirmation with CT angiography or catheter angiography in indeterminate cases. ${ }^{36}$

Several techniques for the endovascular treatment of pseudoaneurysms have been reported in the literature using various embolization agents, such as embolization of the aneurysm neck, embolization proximal to the pseudoaneurysm, and embolization of vessels both distal and proximal to the pseudoaneurysm, the so-called "isolation" or "sandwich" technique. ${ }^{37-39}$ Preference for a specific therapeutic approach must take into consideration several factors such as the anatomical location of the affected vessel, the nature of the artery (expendable with extensive collateral circulation vs. nonexpendable), the size of pseudoaneurysm sac, and the patient's hemodynamic status. ${ }^{33}$

Although embolization of the aneurysmal neck can spare blood flow in the parent artery, infusion of the embolization material may induce rupture due to the fragility of the aneurysm wall. ${ }^{40}$ In addition, this technique increases the risk of migration of embolic materials. ${ }^{41}$ Embolization at a point proximal to the pseudoaneurysm is generally a more straightforward technique but carries a higher risk of failure secondary to blood flow from collateral vessels. It is for this reason that the isolation technique using aneurysm coils is considered the optimal endovascular approach in patients with visceral artery pseudoaneurysms. ${ }^{42}$
In a series of 37 patients with visceral artery pseudoaneurysms embolized with coils using the isolation technique, 32 patients had confirmed complete resolution of pseudoaneurysms on CT scans obtained at 1 day postprocedure, although two cases of recurrence were seen during follow-up. ${ }^{42}$

Several recent studies have reported the effectiveness of transcatheter arterial embolization with N-butyl cyanoacrylate (NBCA) glue. ${ }^{43,44}$ According to Toyoda et al, the hemostasis ratios for acute gastroduodenal bleeding treated by transcatheter arterial embolization with NBCA and transcatheter arterial embolization with gelatin sponge particles and/ or coils are 85.7 and $78.3 \%$, respectively. When the isolation technique cannot be performed, NBCA embolization is recommended as an alternative. ${ }^{40}$

Stent grafts can be used to exclude pseudoaneurysm if the neck is unfavorable or when the parent artery is nonexpendable (e.g., the superior mesenteric artery [SMA]). ${ }^{33}$

Bovine thrombin is also an option as an endovascular embolic agent. Although an off-label use of the thrombin, it has also been used for percutaneous direct puncture and embolization of pseudoaneurysm by injecting thrombin into the pseudoaneurysm as well as the surrounding fluid collection percutaneously under CT guidance. ${ }^{45,46}$

Other materials used for percutaneous direct puncture for pancreatitis-related pseudoaneurysm treatment include glue, ${ }^{47}$ Gelfoam, ${ }^{43}$ PVA (polyvinyl alcohol) particles, ${ }^{48}$ and coils, ${ }^{48}$ with variable success rates.

If there is a concern that high-velocity blood flow will increase the risk of nontarget embolization when using liquid embolic agents and coils, vascular occlusion plugs may be useful, providing a well-controlled and stable occlusion. Vascular occlusion plugs also have the advantage of having a more flexible delivery system when compared with stent 
grafts, and recent advances in technology have seen the introduction of plugs deliverable through a microcatheter. ${ }^{33}$

Overall, transarterial embolization of pancreatitis-related pseudoaneurysms is relatively safe and effective. Recurrence or new pseudoaneurysm formation rates are low and usually occur within 6 months of embolization. ${ }^{49}$

Venous pseudoaneurysms are an extremely rare complication of pancreatitis, with a handful of known cases following pancreatic surgery or abdominal trauma. ${ }^{50,51}$ Spontaneous resolution has been reported, with a natural progression to thrombosis. In another case, a posttraumatic superior mesenteric vein pseudoaneurysm was treated with coiling through a percutaneous transhepatic approach. ${ }^{51}$

\section{Ruptured Pseudoaneurysm into a Pseudocyst (Hemosuccus Pancreaticus)}

A peripancreatic pseudoaneurysm may rarely rupture into a pancreatic pseudocyst, with hemorrhage traveling through the pancreatic duct into the gastrointestinal tract through

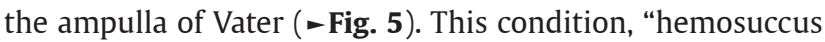
pancreaticus" (HP), was first reported by Sandblom in 1970, with an estimated incidence of 1 in 1,500 cases of acute gastrointestinal hemorrhage. ${ }^{52}$

The most common cause of HP is chronic recurrent pancreatitis related to chronic alcoholism, which results in pancreatic pseudocyst formation. ${ }^{53}$ The peripancreatic vessels most commonly involved are splenic, gastroduodenal, pancreaticoduodenal, gastric, and hepatic arteries..$^{54}$

The most common symptoms are melena and upper abdominal pain. Visualization of spurting blood from the ampulla of Vater is diagnostic. ${ }^{55}$ However, because of the typically intermittent nature of the bleeding, and difficulty visualizing bleeding from the ampulla of Vater using an end-viewing endoscope, upper gastrointestinal endoscopy establishes the diagnosis in only $30 \%$ of cases. ${ }^{56}$ Diagnosis can often be challenging with only a suspicion of a pseudoaneurysm on cross-sectional imaging. Treatment approach is similar to other peripancreatic pseudoaneurysms.

\section{Hemorrhagic Pseudocysts}

As previously described, pseudoaneurysms can be free-standing or can be located within a pseudocyst. Furthermore, pseudocysts can erode into an adjacent artery, forming an expanding hemorrhagic cyst that can rupture into an adjacent hollow organ, or can communicate with the pancreatic duct producing HP. ${ }^{32}$

The overall incidence of bleeding associated with pancreatitis is not well established. The prevalence of bleeding pseudocysts ranges from 2 to $31 \%{ }^{32,57}$ While most life-threatening hemorrhage is arterial in origin, venous bleeding can occur, as well as massive diffuse small vessel hemorrhage associated with pancreatic necrosis.

Spontaneous abdominal hemorrhage can develop at any time in patients with a history of pancreatitis but is often a late complication, with a mean time of occurrence of 2.3 years..$^{32}$ In Balthazar and Fisher's series of 16 patients with pancreatitis-related hemorrhage, bleeding was secondary to pseudoaneurysms in $61 \%$, hemorrhagic pseudocysts in
$19.5 \%$, and severe capillary and venous bleeding associated with pancreatic necrosis in $19.5 \%$.

It is not always possible to identify a single culprit vessel on CT or angiography; hence, surgical treatment is suggested in case of severe venous or diffuse capillary bleeding, hemorrhagic pseudocysts, and unsuccessful embolization (-Fig. 6).

\section{Pancreatic Arteriovenous Malformation Embolization}

Pancreatic AVM (P-AVM) is rare ( 90 cases have been reported)..$^{58}$ They may be congenital in association with hereditary hemorrhagic telangiectasia or Osler-Weber-Rendu's disease. They may also be posttraumatic or occur following pancreatic transplantation, neoplasm, or inflammation. ${ }^{59}$

The majority of patients with P-AVM remain asymptomatic. Gastrointestinal hemorrhage may occur from a ruptured varix secondary to portal hypertension or direct erosion of the AVM into the pancreatic/bile duct or through the adjacent intestinal mucosa as a duodenal ulcer. ${ }^{58}$

The pancreatic head is most commonly involved (56\%) followed by the body and tail (33\%), with the entire pancreas involved in $7 \%$. The definitive treatment for P-AVM has traditionally been surgical resection. ${ }^{60}$ However, Bruno et al described a case of a P-AVM communicating the splenic artery, the superior pancreatic artery, and the splenic vein. ${ }^{61}$ This was treated with coil embolization of the two feeding arteries, with no significant filling of the portal vein on subsequent angiography.

\section{Oncological Interventions}

\section{Percutaneous Biopsy}

Biopsy can be performed intraoperatively, endoscopically, or percutaneously with CT or US guidance. ${ }^{62}$ Percutaneous imaging-guided fine needle aspiration (FNA) has been in use since the 1970s, but it can be challenging to establish a definitive diagnosis of pancreatic adenocarcinoma from cytology samples. As an alternative, image-guided percutaneous biopsy of the pancreas with an automated core biopsy needle has become more commonly used..$^{63}$

A retrospective study by Yang et al reviewed a sampling of 88 pancreatic masses: 13 underwent FNA only, 60 underwent core needle biopsy only, and 15 underwent both. ${ }^{64}$ The diagnostic accuracy of core biopsy alone and both core biopsy and FNA was comparable at $93.3 \%$ and was marginally lower for patients who underwent FNA alone (92.3\%). The negative predictive value was $57 \%$ overall for all biopsies. This is too low for a reliable exclusion of the presence of pancreatic malignancy and suggests that negative results of percutaneous biopsy, whether core or FNA, should be viewed with caution.

\section{Percutaneous Transhepatic Biliary Drainage}

Malignant biliary obstruction is most commonly associated with pancreatic carcinoma, developing in 70 to $90 \%$ of patients and typically leading to jaundice, pruritus, hepatocellular dysfunction, malabsorption coagulopathy, and cholangitis. ${ }^{65}$ Biliary decompression may be achieved by endoscopic retrograde cholangiopancreatography (ERCP) 

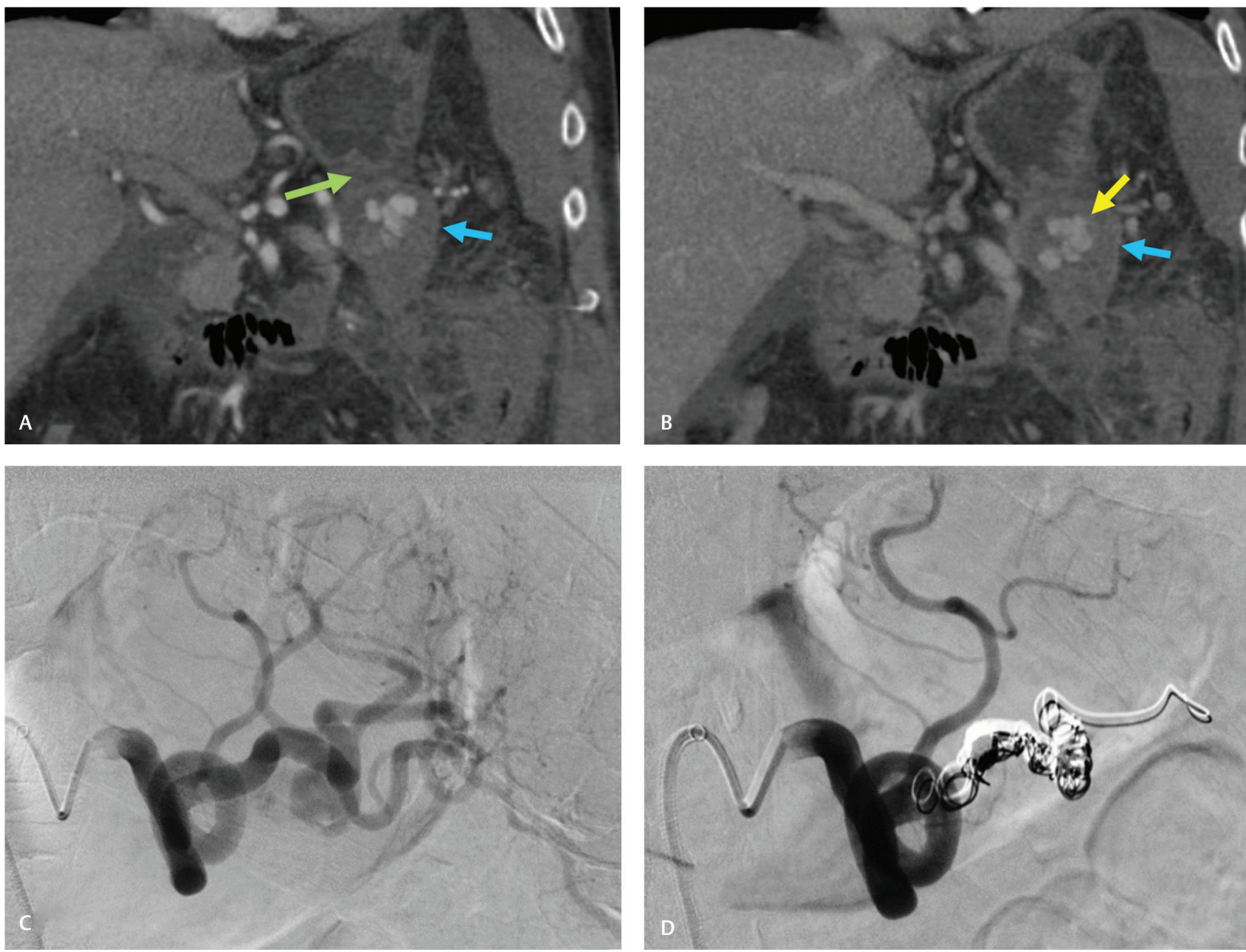

Fig. 5 Coronal reformatted CT (computed tomography) in (A) arterial and (B) portal venous phases in an 89-year-old male patient with massive upper gastrointestinal (GI) hemorrhage. There is evidence of rupture of splenic artery pseudoaneurysm (yellow arrow) into a pancreatic tail pseudocyst (blue arrows). The GI hemorrhage was presumed to be coming from a pseudocyst eroding through the stomach (green arrow). (C, D) This was treated successfully with coil embolization of the splenic artery.
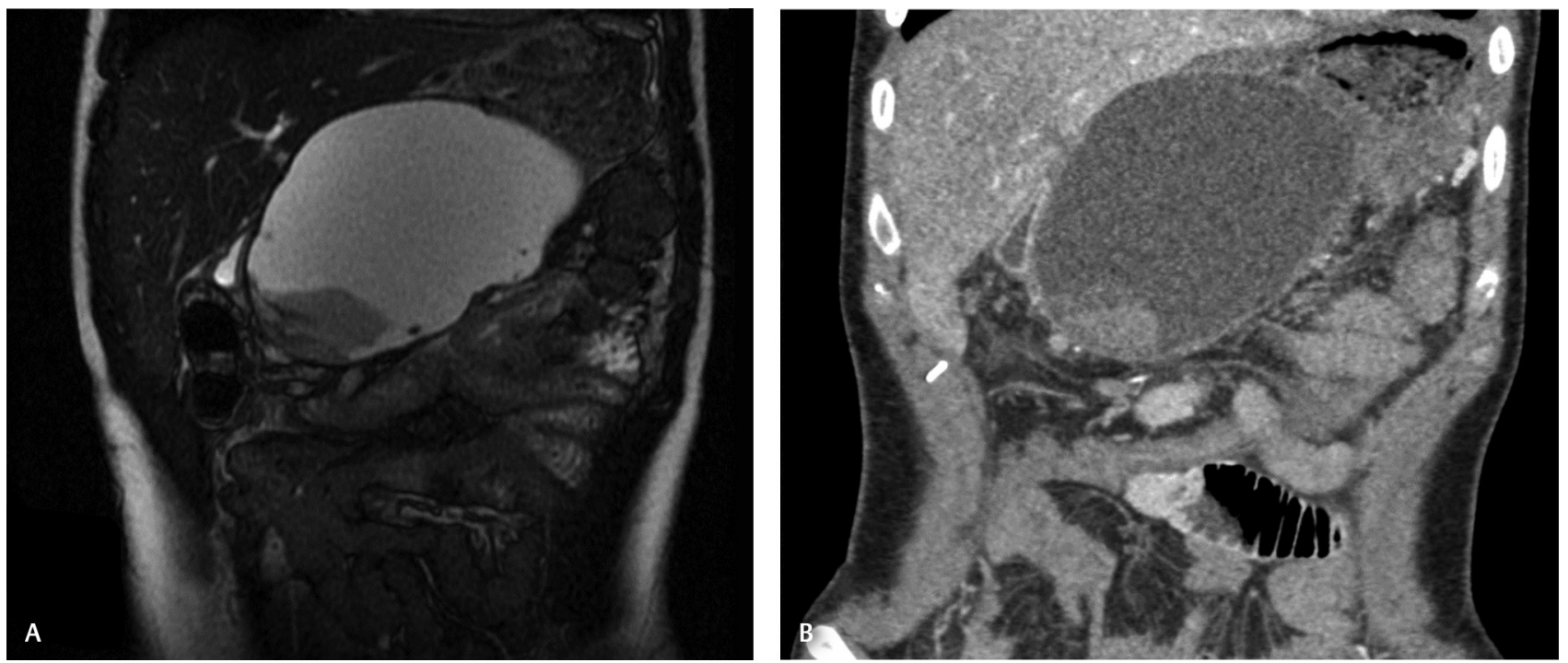

Fig. 6 A 28-year-old male with previous gallstone pancreatitis underwent a follow-up MRI (magnetic resonance imaging) for a known pseudocyst. (A) Coronal FIESTA (fast imaging employing steady-state acquisition) sequence demonstrates isointense material within pancreatic pseudocyst suspicious of hemorrhage. (B) Arterial phase coronal CT (computed tomography) shows high-density material within the cyst in keeping with hemorrhage; however, no pseudoaneurysm was seen. The patient underwent catheter angiography, which did not reveal a site of active contrast extravasation or a pseudoaneurysm (not shown). 
or through percutaneous transhepatic biliary drainage (PTBD).

Endoscopic insertion of plastic or metal stents is technically successful in approximately 90 to 95\% of malignant biliary obstruction cases. ${ }^{66}$ If ERCP fails due to inaccessible papilla due to congenital or surgically altered anatomy, failed cannulation, or the presence of severe tumor-induced stricturing of the bile duct and/or duodenum, PTBD can be undertaken ${ }^{4}$ ( - Fig. 7).

An intrahepatic bile duct branch is accessed (under fluoroscopic and/or US guidance) with an 18- to 22-gauge needle followed by a 0.018-inch guidewire. Puncture with a smaller caliber (22-gauge) needle has been shown to be safer in patients without intrahepatic bile duct dilatation. ${ }^{4}$ Intraductal position is confirmed by a backflow of bile or by fluoroscopic visualization of injected contrast. The 0.018 -inch guidewire is exchanged for a 0.035 -inch guidewire. Depending on operator preference, an access sheath (generally $6 \mathrm{Fr}$ or larger) may be used and the stricture crossed using a catheter and guidewire. After crossing the stricture, the wire is exchanged for a stiff wire. The drainage catheter or stent is then deployed. Internal/external drains must have side holes on each side of the obstruction but not extending into the liver parenchyma as this leads to bile leak. Stents must completely cover the lesion.

Drainage is successful in approximately $95 \%$ of patients with dilated intrahepatic bile ducts but only $70 \%$ of patients with nondilated ducts. ${ }^{67}$

Results from a national audit of 833 patients in the United Kingdom who had undergone PTBD in 2009 showed high immediate technical success for drainage and stenting (>95\%). Minor complications occurred in $26.0 \%$ of patients, the most common being pain (14.3\%), sepsis (7.7\%), and hemorrhage (4.5\%). Major complications occurred in $7.9 \%$ of patients, the most common being hemorrhage (3.5\%), renal failure $(1.8 \%)$, and sepsis (1.6\%). ${ }^{68}$ Data also showed a high inhospital mortality rate (19.8\%) in patients with malignancy. However, this high mortality cannot be entirely attributable to the procedure and is considered to most likely reflect the underlying disease and multiple comorbidities in this patient group. ${ }^{68}$

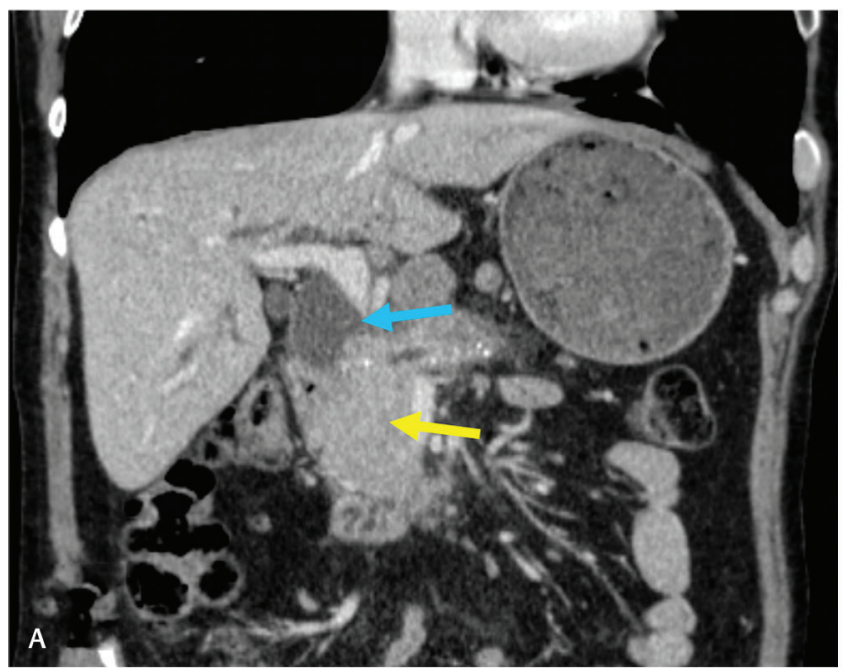

Mortality attributed to percutaneous biliary tract interventions alone is much rarer and ranges from 0.1 to $0.8 \%{ }^{69}$

\section{Ablative Therapies}

Experience and data with pancreatic tumor ablative therapy are regarded as investigational and limited. ${ }^{4}$ Brachytherapy delivered by a percutaneous approach has been found to be minimally effective. Other endoscopic ablative therapies have been trialed, including endoscopic fiducial markers and brachytherapy, photodynamic therapy, EUS-guided radiofrequency ablation (RFA), and EUS-guided alcohol ablation. ${ }^{4}$ We will focus on other nonendoscopic percutaneous interventions including percutaneous RFA, microwave ablation, irreversible electroporation (IRE), and electrochemotherapy (ECT). Their current role in the treatment of pancreatic cancer is still under investigation.

\section{Radiofrequency Ablation}

Wu et al first described open surgical RFA for unresectable pancreatic tumors. ${ }^{70}$ Sixteen patients with unresectable pancreatic cancer were treated by open cool-tip RFA, a with high mortality rate (25\%) due to dramatic direct portal venous gastrointestinal hemorrhage and acute renal failure.

In a later study by Girelli et al, 50 patients with locally advanced pancreatic cancer underwent US-guided RFA during laparotomy. ${ }^{71}$ RFA was the only treatment in 19 patients. RFA was combined with biliary and gastric bypass in 19 patients, gastric bypass alone in 8 , biliary bypass alone in 3 , and pancreaticojejunostomy in 1 . There was only one case of 30-day mortality in this series. The reported RFArelated complications were two cases of pancreatic fistulas and four cases of portal vein thrombosis. ${ }^{71}$

\section{Microwave Ablation}

High-frequency (2.45-GHz) microwave ablation (MWA) for the treatment of unresectable and nonmetastatic locally advanced pancreatic cancer has been trialed by Lygidakis et al. $^{72}$ It has been suggested as a local effective procedure that is feasible and safe, with acceptable minor complications

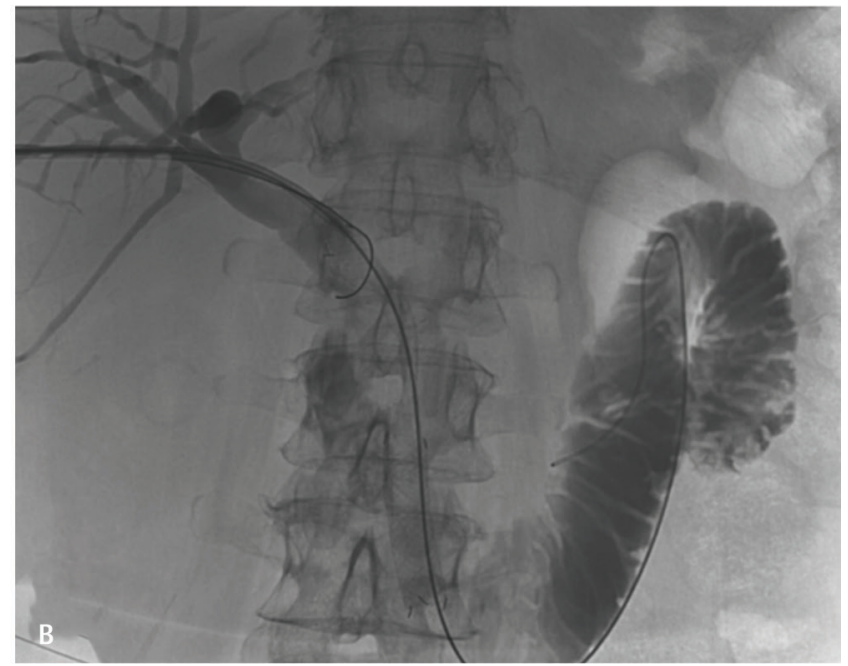

Fig. 7 (A) Coronal reformatted CT (computed tomography) demonstrates pancreatic head tumor (yellow arrow) causing biliary tree dilatation (blue arrow). (B) This was treated with percutaneous transhepatic biliary drainage. 
in locally advanced pancreatic tumors, which can be used as part of a palliative or multimodality treatment.

However, the feasibility and safety of percutaneous MWA approach require further evaluation. ${ }^{72}$

\section{Percutaneous Irreversible Electroporation}

This is a nonthermal ablative technology first described in 2009 by Garcia et al. ${ }^{73}$ It uses high-voltage low-energy direct current through electrodes placed into the pancreas percutaneously under $\mathrm{CT}$ guidance to create permanent pores in the cell membrane, leading to cell death.

The largest retrospective review of patients with pancreatic adenocarcinoma who underwent percutaneous IRE was conducted at Miami Cancer Institute in 2014. ${ }^{74}$ The study included 50 patients with biopsy-proven unresectable pancreatic cancer. The overall survival for the entire cohort from the date of IRE was 14.5 months (95\% confidence interval: $10.4-18.6$ months). Complications occurred in $20 \%$ of patients, including pancreatitis, pain, sepsis, and gastric leak.

\section{Electrochemotherapy}

ECT is an electroporation-based therapy with an already established place in the treatment of cutaneous and liver tumors.

Only one case series (clinical phase I/II) of intraoperative pancreatic ECT with 13 patients has been reported. ${ }^{75}$ Intraoperative electrodes were inserted with US guidance into and around the tumor followed by an intravenous bolus of bleomycin $\left(15,000 \mathrm{IU} / \mathrm{m}^{2}\right)$ and subsequent electric pulses by an electric pulse generator. Treatment was completed within the time window of 8 to 28 minutes after the end of the bleomycin bolus. This time window ensured the maximum concentration of drug within the lesion. No intra- or postoperative serious adverse events related to ECT were observed..$^{75}$

Further research is being undertaken to evaluate the safety and efficacy of this technique in pancreatic cancer treatment. ${ }^{76}$

\section{Interventional Radiology for the Transplanted Pancreas}

Pancreas transplantation is most frequently performed in conjunction with kidney transplantation in the cases of end-stage renal failure secondary to type 1 diabetes. This procedure is known as simultaneous pancreas-kidney transplantation. ${ }^{1}$

The pancreas allograft and a short segment of duodenum are typically placed intraperitoneally in the right side of the abdomen, with the donor kidney generally placed in the left iliac fossa. A donor iliac artery Y-conduit is anastomosed between the SMA and splenic artery of the graft and the common or external iliac artery of the recipient. The venous outflow of the pancreas graft may be drained either systemically into the recipient inferior vena cava or by end-to-side anastomosis from the donor portal vein to the recipient common or external iliac vein.
The pancreatic exocrine enzymes can be drained directly into the enteric circulation by constructing a side-to-side anastomosis between the donor duodenum and the recipient small bowel or recipient bladder ( - Fig. 8).

\section{Vascular Complications of the Transplanted Pancreas}

Vascular complications of the transplanted pancreas can be broadly divided into thrombosis, stenosis, hemorrhage, aneurysms, and AVM.77,78

Imaging investigations usually start with a Doppler study to determine the presence of waveform tracings from the implicated vessel. Suspicious duplex US findings should be evaluated with contrast-enhanced CT or contrast-enhanced magnetic resonance imaging (MRI); these noninvasive modalities have largely replaced catheter angiography as means of diagnosis, although the latter remains the gold standard for the assessment of pancreatic artery complications following transplant. $^{78}$ One advantage of catheter angiography is the ability to proceed directly to endovascular treatment in the same procedure.

\section{Transplant Artery Thrombosis}

This is the most severe posttransplantation vascular complication predisposing the graft to dysfunction and necrosis. ${ }^{1}$ It most commonly occurs within the first 3 months following transplantation.

The symptoms of thrombosis include unexplained hyperglycemia, tenderness over the graft, graft enlargement, and, in bladder-drained grafts, hematuria and decreased urinary amylase. $^{6}$

Accurate and expedient imaging diagnosis of arterial thrombosis is essential because early revascularization

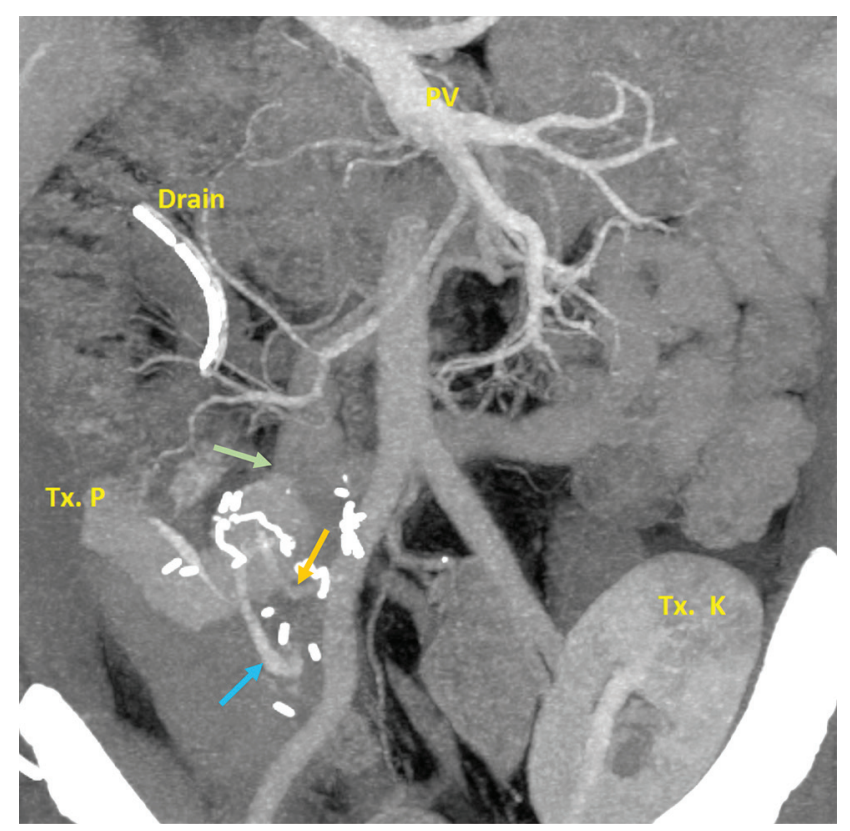

Fig. 8 Simultaneous pancreas-kidney transplantation. Yellow arrow indicates transplant artery graft, blue arrow indicates transplant vein graft, and green arrow indicates duodenojejunal anastomosis. PV, portal vein; Tx K, transplanted kidney; Tx. P, transplanted pancreas. 
with or without thrombectomy may salvage the graft $^{79}$ (-Figs. 9 and 10 ).

Predisposing factors include prolonged cold ischemia, prolonged back-table preparation, graft rejection, pancreatitis, stump thrombi, and vessel trauma. ${ }^{79}$

Complications of pancreas graft thrombosis include graft dysfunction, leakage of pancreatic secretions, pancreatitis, necrosis, and sepsis. Prompt surgical exploration is often required. ${ }^{6}$

\section{Transplant Artery Stenosis}

Arterial stenosis following pancreas transplantation is less common than arterial thrombosis and is typically an early posttransplantation complication. ${ }^{1}$ Predisposing factors include rejection clamp injury, faulty surgical technique, catheter-induced trauma, and disruption of the vasa vasorum. ${ }^{80}$ This is usually assessed with arterial Doppler, with a peak systolic velocity of $2 \mathrm{~m} /$ second or greater being suggestive of an arterial stenosis greater than $50 \%{ }^{1}$

Treatment options for arterial stenosis include angioplasty, covered stent placement in selected cases, and surgical revascularization. ${ }^{81}$ Early treatment with revascularization preserves graft function and often prevents retransplantation (-Fig. 11).

\section{Pancreatic Transplant Hemorrhage}

Intra-abdominal bleeding in the early period after pancreas transplantation is typically associated with systemic anticoagulation initiated to prevent graft thrombosis. ${ }^{6}$ However, delayed hemorrhage is typically secondary to pseudoaneurysm rupture.

In common with treatment of other visceral pseudoaneurysms, endovascular embolization is usually the first line of therapy, offering better morbidity and mortality than open surgical interventions. A covered stent can be deployed in the common/external iliac artery to exclude the pseudoaneurysm (-Fig. 12). Surgical exploration may be necessary when endovascular treatment fails or where hematoma evacuation is required. ${ }^{6}$

\section{Pancreatic Transplant Vein Thrombosis}

Venous thrombosis is the most common cause of early technical pancreatic transplant failure $(70 \%) .{ }^{82}$ Early thrombosis may be associated with acute or hyperacute rejection. However, the majority (60\%) of grafts lost to thrombosis are histopathologically normal.

The etiology is thought to be due to relative stasis caused by compression by a perianastomotic fluid collection, due to phlebitis related to pancreatitis, or because of the shift in organ position, leading to stretching or twisting of the venous anastomosis. ${ }^{83}$

Given that pancreas grafts are predisposed to thrombosis, some propose routine postoperative anticoagulation. ${ }^{84}$ Meticulous surgical technique and rigorous avoidance of the transplant organ damage are considered to be more effective methods to decrease the incidence of early thrombosis. ${ }^{85}$

Endovascular treatments of pancreas transplant venous thrombosis include thrombolysis, mechanical thrombectomy, and deployment of metal stents for anastomotic stenosis or kinks (-Fig. 13). . $^{5}$

\section{Pancreatic Transplant Arteriovenous Fistula Embolization}

An arteriovenous fistula (AVF) is most commonly the consequence of biopsy of the transplanted allograft when the walls of both artery and vein are iatrogenically lacerated. ${ }^{1}$ It, however, can be iatrogenic soon after pancreatic transplantation, as in our case (-Fig. 14).

At duplex US, an AVF is identified as a focal area of aliasing involving a high-velocity low-resistance feeding artery and a pulsatile "arterialized" draining vein. ${ }^{86}$ Dual-phase (arterial and portal venous) CT helps in the characterization and anatomical localization of these vessels.

AVFs may be associated with regional areas of transient parenchymal enhancement on contrast-enhanced CT/MRI. Large AVFs may cause graft ischemia and dysfunction due to arterial "steal" phenomenon. ${ }^{1}$ They are usually treated with transarterial embolization.
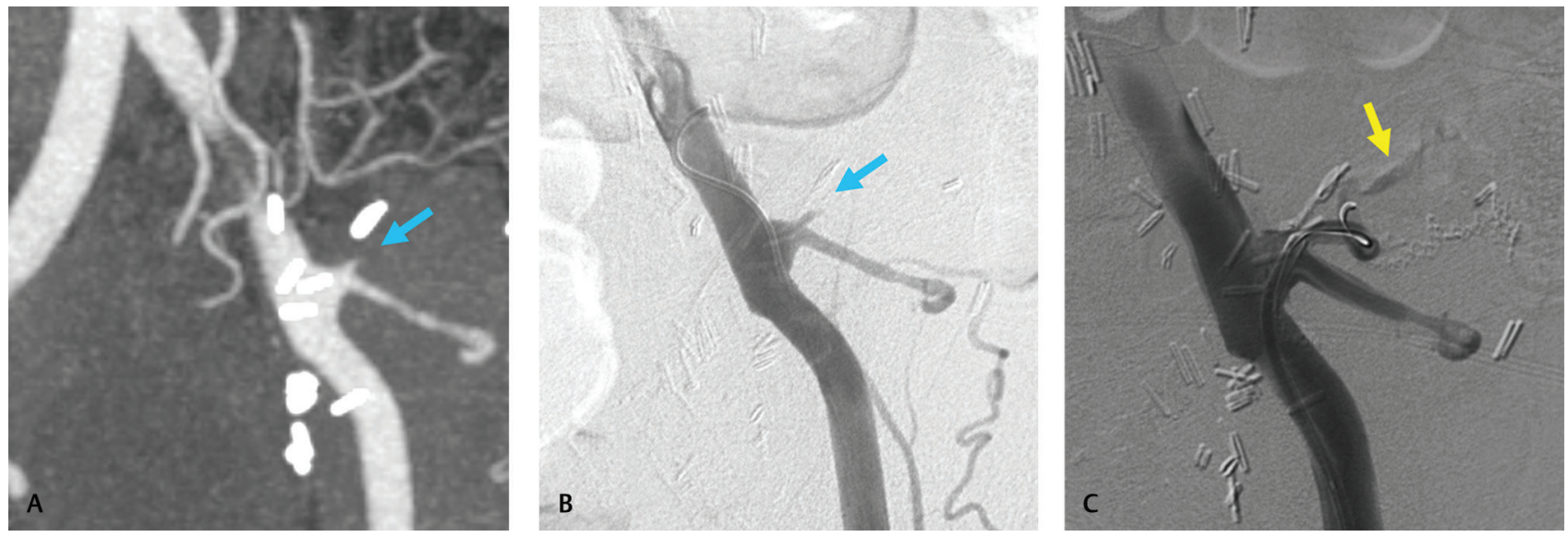

Fig. 9 Blue arrows point to the site of the proximal occlusion of the upper of the two transplanted pancreas arteries on (A) coronal maximum intensity projection reformatted CT (computed tomography) and (B) digital subtraction angiography. Revascularization (yellow arrow) was achieved using 2-mm balloon angioplasty. 

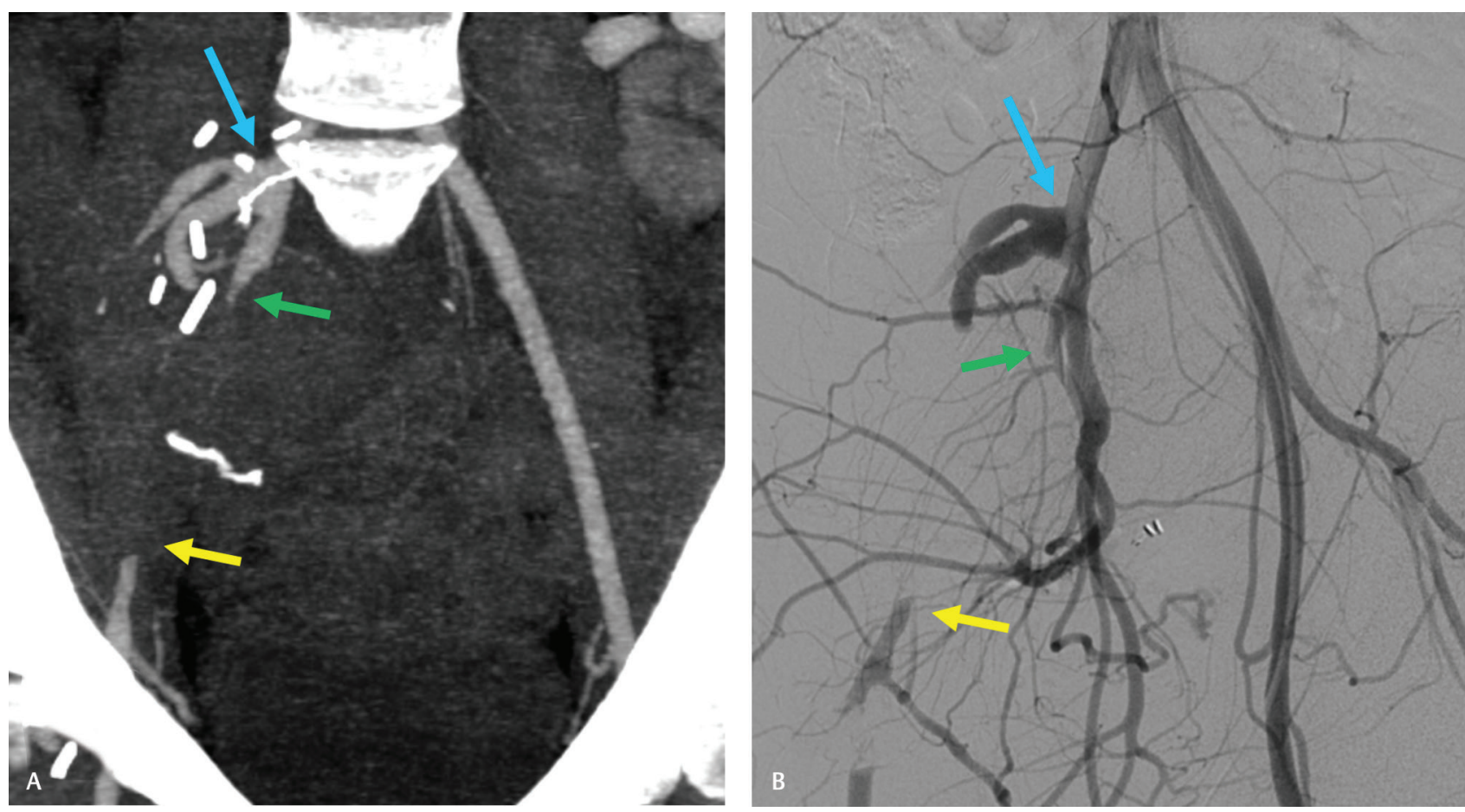

Fig. 10 A 26-year-old female who underwent pancreatic transplantation 4 months previously presented with a firm mass in the right iliac fossa. (A) Computed tomographic angiography (B) digital subtraction angiography show right external iliac artery (EIA) occlusion (green arrow) shortly after $Y$ graft. EIA reforms at the level of the inguinal ligament (yellow arrow). Note that the pancreatic transplant arterial anastomosis is widely patent, and so are both branches (blue arrows). This was treated with a prosthetic vascular graft (not shown).
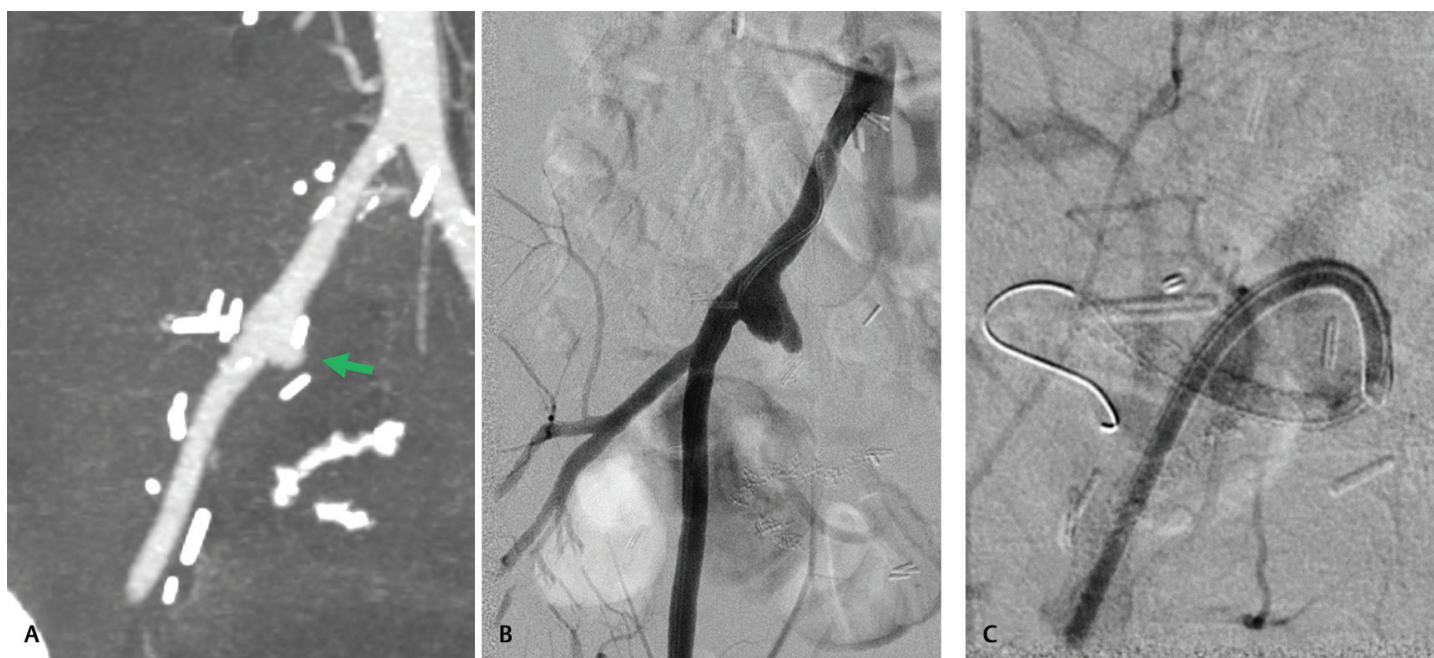

Fig. 11 A 31-year-old male who underwent pancreatic and kidney transplant 4 years previously was admitted with urinary tract infection, sepsis, and right iliac fossa pain. (A) Coronal maximum intensity projection reformatted CT (computed tomography) shows occluded $Y$ graft (green arrow) and no enhancement of the pancreas. (B, C) The patient underwent angioplasty and stent deployment.

\section{Nonvascular Interventions on the Transplanted Pancreas}

Due to the lack of consistent clinical symptoms or markers for rejection, pancreatic biopsies have become the standard method in diagnosing transplant rejection. The biopsy techniques are either through cystoscopy or by percutaneously using US and/or CT guidance, with a reported success rate of $83 \%{ }^{87}$ Cystoscopic biopsies require general anesthesia and only allows biopsy of the pancreatic head. ${ }^{88}$
No major complications occurred in a series of 42 attempted percutaneous biopsies. ${ }^{87}$ However, there is a risk of causing vascular damage to the allograft, including AV fistulation.

Similar to native pancreas percutaneous interventions, drainage of peripancreatic transplant collections can be attempted on the transplanted pancreas with US or CT guidance. 

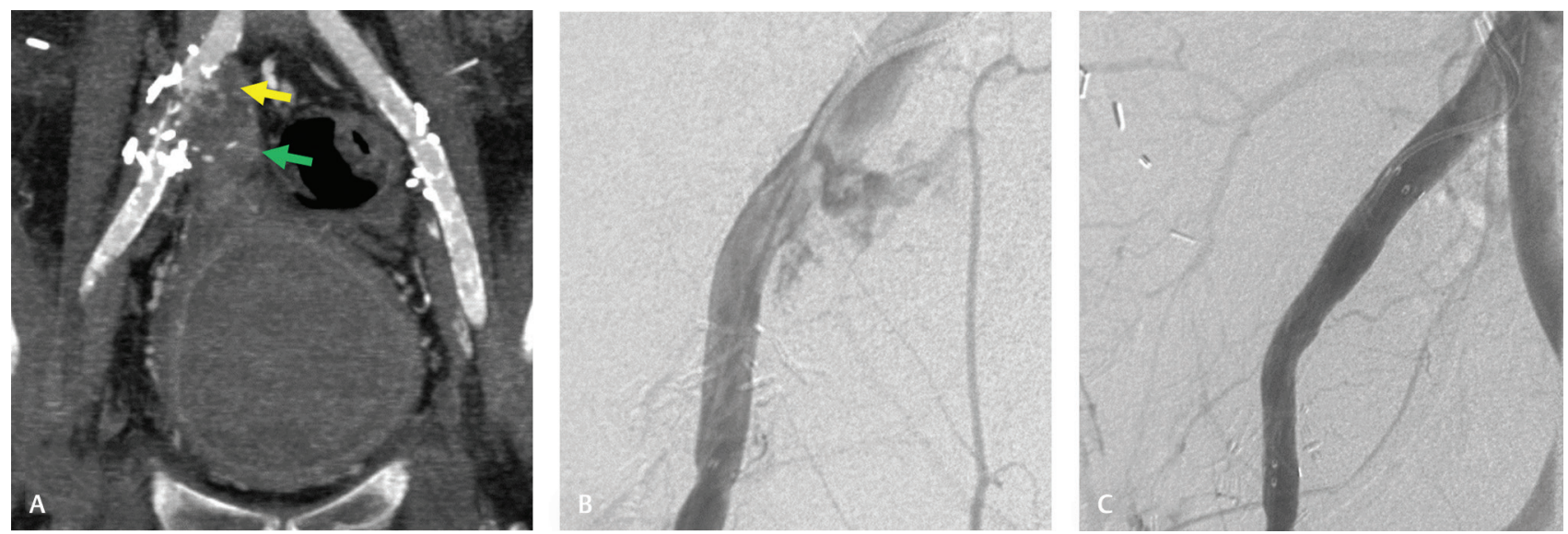

Fig. 12 A 38-year-old female with a previously failed pancreatic transplantation presented with acute hematuria and deranged clotting. (A) Abdominal CT (computed tomography) suggests active hemorrhage (yellow arrow) from the right common iliac artery (CIA) into the bladder through the transplanted pancreas' duodenal pouch (green arrow). (B) Angiography confirms right CIA contrast extravasation. (C) This was treated with a covered stent.
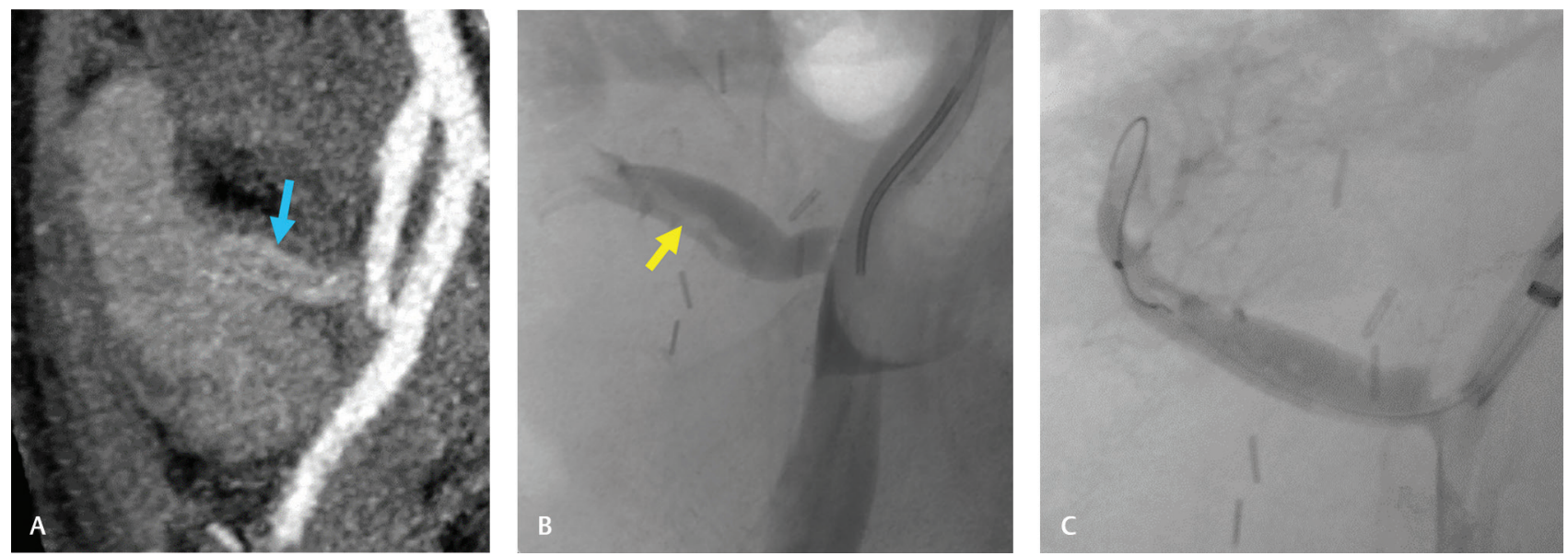

Fig. 13 A 35-year-old female presented with severe hyperglycemia at day 5 following simultaneous pancreas-kidney transplantation. (A) Coronal oblique maximum intensity projection reformatted CT (computed tomography) shows a filling defect within the vein graft in keeping with nonocclusive thrombus (blue arrow). (B) Catheter venography confirms graft thrombus (yellow arrow). (C) This was treated with mechanical thrombectomy.
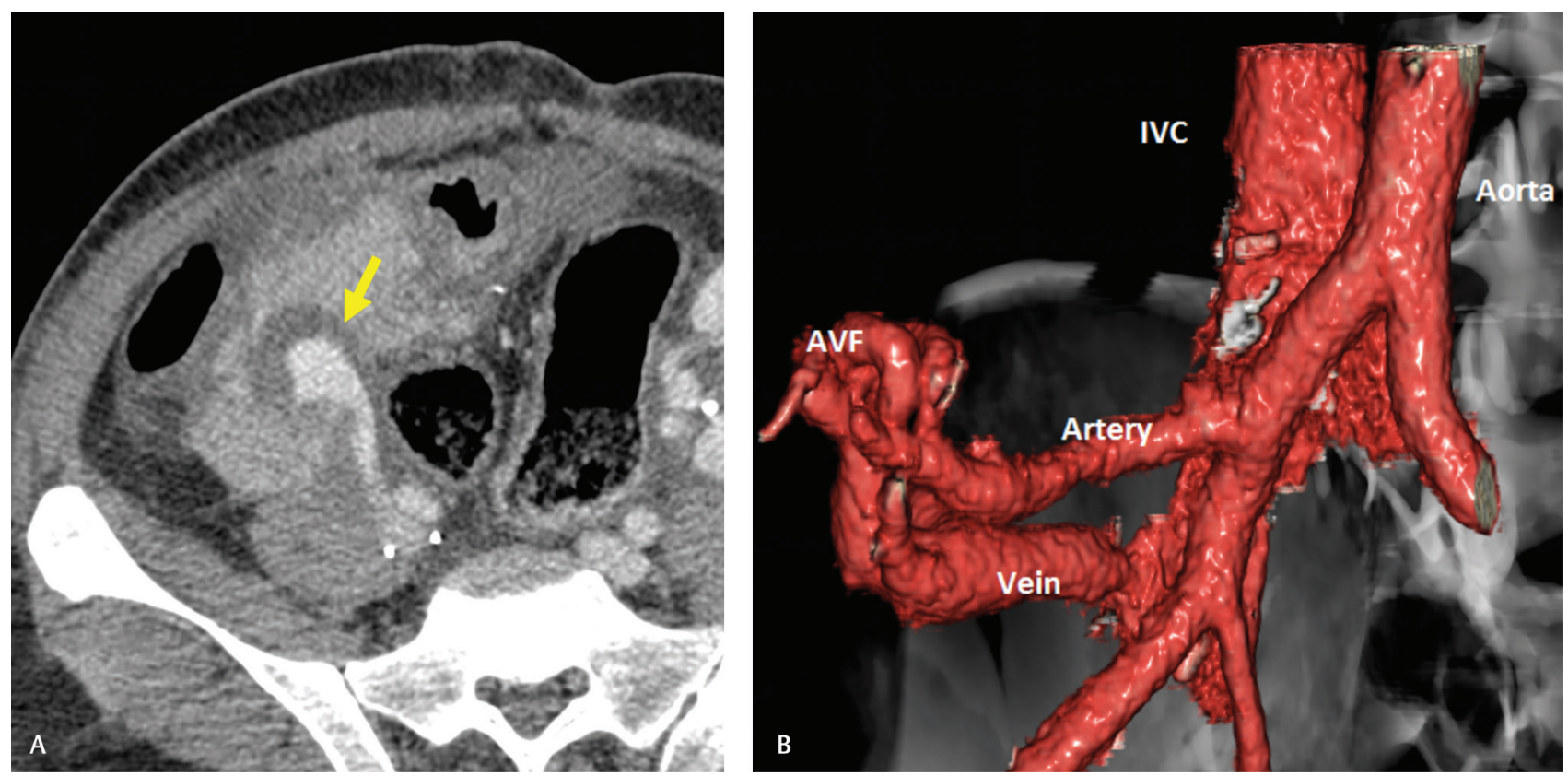

Fig. 14 (A) Axial CT (computed tomography) demonstrates an arteriovenous fistula (AVF) in the transplanted pancreas (yellow arrow). (B) Three-dimensional reconstruction of the AVF. IVC, inferior vena cava. 


\section{Conclusion}

The anatomical location of the pancreas has meant that historically, pancreatic pathologies were treated by either major surgery or conservative means.

Image-guided percutaneous intervention for a wide range of pancreatic disease is now routine.

Vascular complications of pancreatic disease benefit from accurate diagnosis with modern imaging techniques and may require immediate treatment. Endovascular intervention for the treatment of arterial and venous peripancreatic pathology is demonstrably effective.

Ablative techniques from cancer are emerging and may help to alleviate the high morbidity and mortality associated with pancreatic cancer and its treatment.

Vascular complications of the transplanted pancreas can be severe and cause early technical pancreatic transplantation failure. Percutaneous pancreas transplant biopsy has a high success rate and is most accurate in diagnosing transplant rejection. Advances of endovascular interventions permit revascularization and may salvage the graft.

\section{Conflict of Interest}

None declared.

\section{References}

1 Low G, Crockett AM, Leung K, et al. Imaging of vascular complications and their consequences following transplantation in the abdomen. Radiographics 2013;33(3):633-652

2 Bansal A, Gupta P, Singh H, et al. Gastrointestinal complications in acute and chronic pancreatitis. JGH Open; 2019 (e-pub ahead of print). doi:10.1002/jgh3.12185

3 Aswani Y, Hira P. Venous complications of pancreatitis: a review. JOP 2015;16(1):20-24

4 Gleeson FC, Levy MJ. Interventional radiology for pancreatic cancer. In: Pancreatic Cancer. New York, NY: Springer; 2018 815-856

5 Best LM, Rawji V, Pereira SP, Davidson BR, Gurusamy KS. Imaging modalities for characterising focal pancreatic lesions. Cochrane Database Syst Rev 2017;4(4):CD010213

6 Dhanireddy KK. Pancreas transplantation. Gastroenterol Clin North Am 2012;41(1):133-142

7 Cohn JA, Englesbe MJ, Ads YM, et al. Financial implications of pancreas transplant complications: a business case for quality improvement. Am J Transplant 2007;7(6):1656-1660

8 Tyberg A, Karia K, Gabr M, et al. Management of pancreatic fluid collections: a comprehensive review of the literature. World J Gastroenterol 2016;22(7):2256-2270

9 Banks PA, Bollen TL, Dervenis C, et al; Acute Pancreatitis Classification Working Group. Classification of acute pancreatitis-2012: revision of the Atlanta classification and definitions by international consensus. Gut 2013;62(1):102-111

10 Zhao K, Adam SZ, Keswani RN, Horowitz JM, Miller FH. Acute pancreatitis: revised Atlanta classification and the role of cross-sectional imaging. AJR Am J Roentgenol 2015;205(1):W32

11 Akshintala VS, Saxena P, Zaheer A, et al. A comparative evaluation of outcomes of endoscopic versus percutaneous drainage for symptomatic pancreatic pseudocysts. Gastrointest Endosc 2014;79(6):921-928

12 D'Onofrio M, Beleù A, De Robertis R. Ultrasound-guided percutaneous procedures in pancreatic diseases: new techniques and applications. Eur Radiol Exp 2019;3(1):2
13 Working Group IAP/APA Acute Pancreatitis Guidelines. IAP/ APA evidence-based guidelines for the management of acute pancreatitis. Pancreatology 2013;13(4, Suppl 2):e1-e15

14 van Grinsven J, van Santvoort HC, Boermeester MA, et al. Dutch Pancreatitis Study Group. Timing of catheter drainage in infected necrotizing pancreatitis. Nat Rev Gastroenterol Hepatol 2016;13(5):306-312

15 van Grinsven J, van Dijk SM, Dijkgraaf MG, et al. Dutch Pancreatitis Study Group. Postponed or immediate drainage of infected necrotizing pancreatitis (POINTER trial): study protocol for a randomized controlled trial. Trials 2019;20(1):239

16 Mauri G, Mattiuz C, Sconfienza LM, et al. Role of interventional radiology in the management of complications after pancreatic surgery: a pictorial review. Insights Imaging 2015;6(2):231-239

17 Nealon WH, Bhutani M, Riall TS, Raju G, Ozkan O, Neilan R. A unifying concept: pancreatic ductal anatomy both predicts and determines the major complications resulting from pancreatitis. J Am Coll Surg 2009;208(5):790-799

18 Swartz DK, Obando J. Endoscopic management of peri-pancreatic collections. Gastroenterol Res Pract 2012;2012:906381

19 Shamah S, Okolo PI III. Systematic review of endoscopic cyst gastrostomy. Gastrointest Endosc Clin N Am 2018; 28(4):477-492

20 Khreiss M, Zenati M, Clifford A, et al. Cyst gastrostomy and necrosectomy for the management of sterile walled-off pancreatic necrosis: a comparison of minimally invasive surgical and endoscopic outcomes at a high-volume pancreatic center. J Gastrointest Surg 2015;19(8):1441-1448

21 Henriksen FW, Hancke S. Percutaneous cystogastrostomy for chronic pancreatic pseudocyst. $\mathrm{Br} \mathrm{J}$ Surg 1994;81(10):1525-1528

22 Hackert T, Werner J, Büchler MW. Postoperative pancreatic fistula. Surgeon 2011;9(4):211-217

23 Sohn TA, Yeo CJ, Cameron JL, et al. Resected adenocarcinoma of the pancreas-616 patients: results, outcomes, and prognostic indicators. J Gastrointest Surg 2000;4(6):567-579

24 Jiang W, Tong Z, Yang D, et al. Gastrointestinal fistulas in acute pancreatitis with infected pancreatic or peripancreatic necrosis: a 4-year single-center experience. Medicine (Baltimore) 2016;95(14):e3318

25 Pedicini V, Poretti D, Mauri G, et al. Management of post-surgical biliary leakage with percutaneous transhepatic biliary drainage (PTBD) and occlusion balloon (OB) in patients without dilatation of the biliary tree: preliminary results. Eur Radiol 2010;20(5):1061-1068

26 Mauri G, Sconfienza LM, Fiore B, et al. Post-surgical enteric fistula treatment with image-guided percutaneous injection of cyanoacrylic glue. Clin Radiol 2013;68(1):59-63

27 Gmeinwieser J, Holstege A, Zirngibl H, et al. Successful percutaneous treatment of infected necrosis of the body of the pancreas associated with segmental disruption of the main pancreatic duct. Gastrointest Endosc 2000;52(3):413-415

28 Farthmann EH, Lausen M, Schöffel U. Indications for surgical treatment of acute pancreatitis. Hepatogastroenterology 1993;40(6):556-562

29 Logue JA, Carter CR. Minimally invasive necrosectomy techniques in severe acute pancreatitis: role of percutaneous necrosectomy and video-assisted retroperitoneal debridement. Gastroenterol Res Pract 2015;2015(4):693040

30 Seifert H, Biermer M, Schmitt W, et al. Transluminal endoscopic necrosectomy after acute pancreatitis: a multicentre study with long-term follow-up (the GEPARD Study) Gut 2009;58(9):1260-1266

31 Nardis P. IR management of pancreatitis: optimal drainage strategies. Presented at the Annual Meeting of the Cardiovascular and Interventional Radiological Society of Europe (CIRSE), Copenhagen, Denmark, September 16-20; 2017 
32 Balthazar EJ, Fisher LA. Hemorrhagic complications of pancreatitis: radiologic evaluation with emphasis on $\mathrm{CT}$ imaging. Pancreatology 2001;1(4):306-313

33 Zabicki B, Limphaibool N, Holstad MJV, Juszkat R. Endovascular management of pancreatitis-related pseudoaneurysms: a review of techniques. PLoS One 2018;13(1):e0191998

34 Tessier DJ, Stone WM, Fowl RJ, et al. Clinical features and management of splenic artery pseudoaneurysm: case series and cumulative review of literature. J Vasc Surg 2003;38(5):969-974

35 Vander Mijnsbrugge W, Laleman W, Van Steenbergen W, Heye S, Verslype C, Maleux G. Long-term clinical and radiological outcome of endovascular embolization of pancreatitis-related pseudoaneurysms. Acta Radiol 2017;58(3):316-322

36 Bharwani N, Patel S, Prabhudesai S, Fotheringham T, Power N. Acute pancreatitis: the role of imaging in diagnosis and management. Clin Radiol 2011;66(2):164-175

37 Iwama Y, Sugimoto K, Zamora CA, et al. Transcatheter embolization of splenic artery pseudo-aneurysm rupturing into colon after post-operative pancreatitis. Cardiovasc Intervent Radiol 2006;29(1):133-136

38 Murata S, Tajima H, Fukunaga T, et al. Management of pancreaticoduodenal artery aneurysms: results of superselective transcatheter embolization. AJR Am J Roentgenol 2006;187(3):W290-W298

39 Carmeci C, McClenathan J. Visceral artery aneurysms as seen in a community hospital. Am J Surg 2000;179(6):486-489

40 Parildar M, Oran I, Memis A. Embolization of visceral pseudoaneurysms with platinum coils and N-butyl cyanoacrylate. Abdom Imaging 2003;28(1):36-40

41 Takahashi T, Shimada K, Kobayashi N, Kakita A. Migration of steel-wire coils into the stomach after transcatheter arterial embolization for a bleeding splenic artery pseudoaneurysm: report of a case. Surg Today 2001;31(5):458-462

42 Ikeda O, Nakasone Y, Tamura Y, Yamashita Y. Endovascular management of visceral artery pseudoaneurysms: transcatheter coil embolization using the isolation technique. Cardiovasc Intervent Radiol 2010;33(6):1128-1134

43 Toyoda H, Nakano S, Kumada T, et al. Estimation of usefulness of N-butyl-2-cyanoacrylate-lipiodol mixture in transcatheter arterial embolization for urgent control of life-threatening massive bleeding from gastric or duodenal ulcer. J Gastroenterol Hepatol 1996;11(3):252-258

44 Kish JW, Katz MD, Marx MV, Harrell DS, Hanks SE. N-butyl cyanoacrylate embolization for control of acute arterial hemorrhage. J Vasc Interv Radiol 2004;15(7):689-695

45 Puri S, Nicholson AA, Breen DJ. Percutaneous thrombin injection for the treatment of a post-pancreatitis pseudoaneurysm. Eur Radiol 2003;13(6, Suppl 4):L79-L82

46 Michimoto K, Higuchi T, Enoki K, Matsui Y, Takenaga S, Saeki C. Percutaneous puncture and embolisation for pancreatitis-related pseudoaneurysm: the feasibility of thrombin injection even in collection of fluid surrounding the pseudoaneurysm. Pol J Radiol 2018;83:e510-e513

47 Petersen B, Barkun A, Carpenter S, et al; Technology Assessment Committee, American Society for Gastrointestinal Endoscopy. Tissue adhesives and fibrin glues. Gastrointest Endosc 2004;60(3):327-333

48 Shrivastava A, Rampal JS, Reddy DN, Rao GV. Direct needle puncture and embolization of splenic artery pseudoaneurysm in case of chronic atrophic calcific pancreatitis. Pol J Radiol 2016;81:462-464

49 Hyare H, Desigan S, Brookes JA, Guiney MJ, Lees WR. Endovascular management of major arterial hemorrhage as a complication of inflammatory pancreatic disease. J Vasc Interv Radiol 2007;18(5):591-596
50 Mendelson RM, Anderson J, Marshall M, Ramsay D. Vascular complications of pancreatitis. ANZ J Surg 2005;75(12):1073-1079

51 Kwon H, Kim C, Jeon C. Isolated pancreaticoduodenal vein injury from blunt abdominal trauma successfully treated by endovascular treatment. Presented at the Annual Meeting of the Cardiovascular and Interventional Radiological Society of Europe ( CIRSE), Copenhagen, Denmark, September 16-20; 2017

52 Mandaliya R, Krevsky B, Sankineni A, Walp K, Chen O. Hemosuccus pancreaticus: a mysterious cause of gastrointestinal bleeding. Gastroenterol Res 2014;7(1):32-37

53 Ray S, Das K, Ray S, Khamrui S, Ahammed M, Deka U. Hemosuccus pancreaticus associated with severe acute pancreatitis and pseudoaneurysms: a report of two cases JOP 2011;12(5):469-472

54 Woods MS, Traverso LW, Kozarek RA, Brandabur J, Hauptmann E. Successful treatment of bleeding pseudoaneurysms of chronic pancreatitis. Pancreas 1995;10(1):22-30

55 Hyare H, Desigan S, Nicholl H, Guiney MJ, Brookes JA, Lees WR. Multi-section CT angiography compared with digital subtraction angiography in diagnosing major arterial hemorrhage in inflammatory pancreatic disease. Eur J Radiol 2006;59(2):295-300

56 Ullah W, Hamid M, Sarwar U, Mehmood A. Pseudo to pseudo connection: pseudoaneurysm draining into the pseudocyst causing pseudohaemobillia. BMJ Case Rep 2019;12(3):e228441

57 Kelly SB, Gauhar T, Pollard R. Massive intraperitoneal hemorrhage from a pancreatic pseudocyst. Am J Gastroenterol 1999;94(12):3638-3641

58 Lee M, Marusawa H, Yamashita Y. Education and imaging. Gastrointestinal: recurrent pancreatitis due to pancreatic arteriovenous malformation. J Gastroenterol Hepatol 2015;30(1):2-2

59 Barbuscio I, Fantin A, Ghisa M, Moletta L, Sperti C, Farinati F. A tricky case of pancreatic arteriovenous malformation: the role of endoscopic ultrasound in the diagnosis of this rare condition. Endoscopy 2019;51(2):195-196

60 Yamabuki T, Ohara M, Kimura N, et al. Pancreatic arteriovenous malformation. Case Rep Gastroenterol 2014;8(1):26-31

61 Bruno A, Mengozzi E, Affinita A, et al. Embolization of pancreatic arteriovenous malformation in a patient with intestinal bleeding. Presented at the Annual Meeting of the Cardiovascular and Interventional Radiological Society of Europe ( CIRSE), Lisbon, Portugal, September 22-25; 2018

62 Harter LP, Moss AA, Goldberg HI, Gross BH. CT-guided fine-needle aspirations for diagnosis of benign and malignant disease. AJR Am J Roentgenol 1983;140(2):363-367

63 Paulsen SD, Nghiem HV, Negussie E, Higgins EJ, Caoili EM, Francis IR. Evaluation of imaging-guided core biopsy of pancreatic masses. AJR Am J Roentgenol 2006;187(3):769-772

64 Yang RY, Ng D, Jaskolka JD, Rogalla P, Sreeharsha B. Evaluation of percutaneous ultrasound-guided biopsies of solid mass lesions of the pancreas: a center's 10-year experience. Clin Imaging 2015;39(1):62-65

65 Warshaw AL, Fernández-del Castillo C. Pancreatic carcinoma. N Engl J Med 1992;326(7):455-465

66 Knyrim K, Wagner HJ, Pausch J, Vakil N. A prospective, randomized, controlled trial of metal stents for malignant obstruction of the common bile duct. Endoscopy 1993;25(3):207-212

67 Katsinelos P, Paroutoglou G, Kountouras J, et al. A comparative study of standard ERCP catheter and hydrophilic guide wire in the selective cannulation of the common bile duct. Endoscopy 2008;40(4):302-307

68 Uberoi R, Das N, Moss J, Robertson I. The British Society of Interventional Radiology: Biliary Drainage and Stenting Registry (BDSR). Cardiovasc Intervent Radiol 2012;35(1):127-138 
69 Venkatanarasimha N, Damodharan K, Gogna A, et al. Diagnosis and management of complications from percutaneous biliary tract interventions. Radiographics 2017;37(2):665-680

$70 \mathrm{Wu} \mathrm{Y,} \mathrm{Tang} \mathrm{Z,} \mathrm{Fang} \mathrm{H,} \mathrm{et} \mathrm{al.} \mathrm{High} \mathrm{operative} \mathrm{risk} \mathrm{of} \mathrm{cool-tip}$ radiofrequency ablation for unresectable pancreatic head cancer. J Surg Oncol 2006;94(5):392-395

71 Girelli R, Frigerio I, Salvia R, Barbi E, Tinazzi Martini P, Bassi C. Feasibility and safety of radiofrequency ablation for locally advanced pancreatic cancer. Br J Surg 2010;97(2):220-225

72 Lygidakis NJ, Sharma SK, Papastratis P, et al. Microwave ablation in locally advanced pancreatic carcinoma-a new look. Hepatogastroenterology 2007;54(77):1305-1310

73 Garcia PA, Rossmeisl JH, Robertson J, Ellis TL, Davalos RV. Pilot study of irreversible electroporation for intracranial surgery. Conf Proc IEEE Eng Med Biol Soc 2009;2009:6513-6516

74 Narayanan G, Hosein PJ, Beulaygue IC, et al. Percutaneous image-guided irreversible electroporation for the treatment of unresectable, locally advanced pancreatic adenocarcinoma. J Vasc Interv Radiol 2017;28(3):342-348

75 Granata V, Fusco R, Piccirillo M, et al. Electrochemotherapy in locally advanced pancreatic cancer: preliminary results. Int J Surg 2015;18:230-236

76 Dezman R, Serša G, Seliskar A, et al. Percutaneous electrochemotherapy of the pancreas is feasible and safe in a porcine survival model. Presented at the European Conference on Interventional Oncology Amsterdam, the Netherlands April 8-11; 2019

77 Laftavi MR, Gruessner A, Gruessner R. Surgery of pancreas transplantation. Curr Opin Organ Transplant 2017;22(4):389-397

78 Kayahan Ulu EM, Coskun M, Ozbek O, et al. Accuracy of multidetector computed tomographic angiography for detecting hepatic artery complications after liver transplantation. Transplant Proc 2007;39(10):3239-3244
79 Vandermeer FQ, Manning MA, Frazier AA, Wong-You-Cheong $\mathrm{JJ}$. Imaging of whole-organ pancreas transplants. Radiographics 2012;32(2):411-435

80 Bhargava P, Vaidya S, Dick AA, Dighe M. Imaging of orthotopic liver transplantation. review AJR Am J Roentgenol 2011 196(3 Suppl):WS15-WS25, quiz S35-S38

81 Kobayashi K, Censullo ML, Rossman LL, Kyriakides PN, Kahan $\mathrm{BD}$, Cohen AM. Interventional radiologic management of renal transplant dysfunction: indications, limitations, and technical considerations. Radiographics 2007;27(4):1109-1130

82 Troppmann C, Gruessner AC, Benedetti E, et al. Vascular graft thrombosis after pancreatic transplantation: univariate and multivariate operative and nonoperative risk factor analysis. J Am Coll Surg 1996;182(4):285-316

83 Tolat PP, Foley WD, Johnson C, Hohenwalter MD, Quiroz FA. Pancreas transplant imaging: how I do it. Radiology 2015;275(1):14-27

84 Hopt UT, Büsing M, Schareck W, et al. Prevention of early postoperative graft thrombosis in pancreatic transplantation. Transplant Proc 1993;25(4):2607-2608

85 Stockland AH, Willingham DL, Paz-Fumagalli R, et al. Pancreas transplant venous thrombosis: role of endovascular interventions for graft salvage. Cardiovasc Intervent Radiol 2009;32(2):279-283

86 Brown ED, Chen MY, Wolfman NT, Ott DJ, Watson NE Jr. Complications of renal transplantation: evaluation with US and radionuclide imaging. Radiographics 2000;20(3):607-622

87 Lee BC, McGahan JP, Perez RV, Boone JM. The role of percutaneous biopsy in detection of pancreatic transplant rejection. Clin Transplant 2000;14(5):493-498

88 McGahan J, Anderson M, Babcook C, Semonsen K, Perez R. Pancreatic transplant-value of colour flow ultrasound-guided biopsy. J Interv Radiol 1995;10(4):121-124 
